\title{
COMUNIDADES ECLESIAIS DE BASE (CEBs): DE MEDELLÍN-PUEBLA AOS NOSSOS DIAS
}

\author{
Basic Ecclesial Communities: from Medellin-Puebla to our times \\ Comunidades Eclesiales de Base (CEBs): desde Medellín-Puebla hasta nuestros días
}

Francisco de Aquino JÚNior ${ }^{\mathrm{I}}$

\section{Resumo}

As Comunidades Eclesiais de Base (CEBs) marcaram decisivamente a vida da Igreja da América Latina na segunda metade do século passado, como se pode constatar nos documentos das conferências do episcopado latino-americano em Medellín (1968) e Puebla (1979). E tanto no que diz respeito à sua missão evangelizadora (salvação-libertação-opçâo pelos pobres), quando no que diz respeito à sua estrutura social (comunidade carismas e ministérios). Elas aparecem nesses documentos como projeto pastoral ou, em todo caso, um elemento ou aspecto fundamental do projeto pastoral que se propóe para o conjunto da Igreja no continente. E isso se pode verificar na caminhada/história da Igreja latino-americana nesse período. Mas essa situação mudou radicalmente a partir do final dos anos 80, sobretudo a partir da conferência de Santo Domingo (1992). De projeto pastoral ou elemento fundamental de um projeto pastoral, passam a ser tratadas (ou mesmo toleradas) como um grupo ou movimento entre outros. E essa situação não muda radicalmente nem mesmo com a Conferência de Aparecida (2007). Esse artigo trata precisamente da importância e do lugar das CEBs nesses diferentes contextos eclesiais. Começa tratando das CEBs nas conferências de Medellín e de Puebla e, em seguida, faz algumas consideraçóes sobre os desafios e as perspectivas para as CEBs no atual contexto eclesial. A primeira parte do estudo é mais de cunho analítico (análise de textos). Já a segunda parte do estudo é mais de caráter reflexivo (reflexão sobre a atual conjuntura eclesial).

1 Doutor em Teologia pela Westfälische Wilhelms-Universität Münster, Alemanha. Professor de Teologia da Faculdade Católica de Fortaleza (FCF) e da Universidade Católica de Pernambuco (UNICAP), Brasil. Presbítero da Diocese de Limoeiro do Norte - CE, Brasil. Correo electrónico: axejun@yahoo.com.br 
Palavras-chave: Concílio; Povo de Deus; Medellín-Puebla; Comunidades Eclesiais de Base; CEBs; Novo contexto eclesial.

\section{Abstract}

Basic Ecclesial Communities (BEC) became a milestone in the life of Latin American Church during the second half of the last century both for the evangelizing mission (salvation-liberation-option for the poor) and social structure (charismatic communities and ministries), as can be evidenced in the documents of the Episcopal Conferences of Latin America in Medellin (1968) and Puebla (1979). In the documents, these communities are deemed as a pastoral project or, at least, an essential aspect of the pastoral project suggested for the entire Church of the region. However, this began to change drastically at the end of the eighties, especially since the Santo Domingo Conference (1992). From being a pastoral project or essential aspect of a pastoral project, BECs became one group among others (even one that had to be tolerated). The latter has not changed, not even after the Aparecida Conference (2007). Bearing this in mind, the article deals with the relevance and place of BECs within different ecclesial contexts. First, it deals with BECs within the conferences of Medellin and Puebla, and, then, it considers some of the challenges and perspectives for BECs within the current ecclesial context. Thus, the first part of the article is of analytic nature in which an analysis of the documents is carried out, and the second one is reflective and presents some thoughts regarding the current ecclesial context.

Keywords: Council; Medellin-Puebla; People of God; Basic Ecclesial Communities; BEC; New Ecclesial Context.

\section{Resumen}

Las Comunidades Eclesiales de Base (CEBs) marcaron decisivamente la vida de la Iglesia de América Latina en la segunda mitad del siglo pasado, como puede constatarse en los documentos de las conferencias del episcopado latinoamericano en Medellín (1968) y Puebla (1979). Tanto en lo que se dice con respecto a su misión evangelizadora (salvación-liberación-opción por los pobres), como en lo que se refiere a su estructura social (comunidad-carismas y ministerios). Estas aparecen en estos documentos como proyecto pastoral o, en todo caso, como un elemento o aspecto fundamental del proyecto pastoral que se propone para el conjunto de la Iglesia en el continente. Esto se puede verificar en el camino/historia de la Iglesia latinoamericana en ese periodo. Pero esa situación cambió radicalmente a partir de finales de los años 80 , sobre todo a partir de la conferencia de Santo Domingo (1992). De proyecto pastoral o elemento fundamental de un proyecto pastoral pasan a ser tratadas (incluso toleradas) como un grupo o movimiento entre otros. Y esa situación no cambia radicalmente ni siquiera con la Conferencia de Aparecida (2007). Este artículo trata precisamente de la importancia y del lugar de las CEBs en esos diferentes contextos eclesiales. Comienza tratando de las CEBs en las conferencias de Medellín y de Puebla y, enseguida, hace algunas consideraciones sobre los desafíos y las perspectivas para las CEBs en el actual contexto eclesial. La primera parte del estudio es de tipo analítico: se hace un análisis de textos. Ya la segunda parte es de carácter reflexivo, se hace una reflexión sobre la coyuntura eclesial actual.

Palabras clave: Concilio; Pueblo de Dios; Medellín-Puebla; Comunidades Eclesiales de Base; CEBs; Nuevo contexto eclesial. 


\section{Introdução}

Embora se possa discutir se a Constituição Dogmática Lumen Gentium deva ser considerada a "pedra angular" de todos os documentos conciliares (PHILIPS, 1968, p. 1), não se pode negar que desde o final da primeira seção, sob forte influência dos cardeais Suenens e Montini, foi se impondo cada vez mais a tese de que a discussão sobre a Igreja era o grande objetivo do Concílio Vaticano II. Nessa discussão, um ponto fundamental diz respeito à estrutura social da Igreja que é inseparável de sua missão de ser "sinal e instrumento" de salvação ou do reinado de Deus no mundo.

É verdade que o Vaticano II não superou completamente a compreensão clerical clássica da Igreja, formulada em termos de "hierarquia e laicato". Mas, ao começar falando do "povo de Deus" e, só depois, distinguir nesse povo os vários carismas e ministérios, o Concílio lançou as bases para uma compreensão da Igreja como "comunhão", que depois será explicitada e formulada em termos de "comunidade - carismas e ministérios" (CNBB, 2012, n. 104-105).

Essa nova compreensão da Igreja encontrou nas Comunidades Eclesiais de Base (CEBs) na América Latina sua expressão mais básica, criativa e fecunda. A Igreja como povo de Deus com seus carismas e ministérios se realiza primariamente em comunidades de base que se constituem como lugar de oração, vida fraterna e compromisso com os pobres e marginalizados; como lugar onde se exercitam e se desenvolvem carismas e ministérios importantes e necessários para a vida da comunidade e o exercício de sua missão no mundo. Essas comunidades de base são em si mesmas e simultaneamente "sinal" (expressão) e "instrumento" (mediação) de salvação ou do reinado de Deus no mundo.

Aqui está uma das intuiçóes e uma das marcas mais importantes e mais originais do processo de recepção do Concílio na América Latina: A tradução/concretização do "povo de Deus" em termos de "comunidade eclesial de base". Certamente, a Igreja como povo de Deus não se esgota na comunidade de base, mas tem aí sua expressão mais elementar e mais fundamental. E, certamente, a Igreja latino-americana desenvolveu muitos outros processos criativos e fecundos de comunhão eclesial (colegialidade episcopal, compreensão e exercício do ministério episcopal e presbiteral, vida religiosa inserida, carismas e ministérios, estruturas de coordenação pastoral etc.), mas todos esses processos, de alguma forma, estáo vinculados a essa expressão básica e fundamental do povo de Deus que é a comunidade eclesial de base.

As CEBs marcaram decisivamente o processo de recepção do Concílio na América Latina e por décadas se impuseram como o fato eclesial e social mais importante de nossa Igreja. Sobre elas já se escreveu muito, tanto do ponto de vista teológico-pastoral, quanto do ponto de vista sociocultural (MATOS, 1985; MUÑOZ, 1985; TEIXEIRA, 1988; BOFF, L, 1991; BOFF, C, 1997). Um aspecto decisivo, embora tenso e ambíguo, para essa importância das CEBs é o caráter institucional que elas adquirem nas conferências de Medellín e Puebla. Elas aparecem nos documentos finais dessas conferências não apenas como uma experiência identificada e até valorizada na América Latina, mas como projeto pastoral ou, em todo caso, como parte integrante e fundamental do projeto pastoral que se desenha e se propóe para o conjunto da Igreja latino-americana. É verdade que isso nunca foi táo tranquilo e consensual como pode parecer à primeira vista e que foi, inclusive, um dos pontos tensos e controversos em Puebla. Mas náo se pode minimizar o fato de que, em meio a tensões e conflitos, elas foram assumidas oficialmente como orientação/ 
proposta pastoral para todo o continente e que isso foi assumido por uma parte significativa da Igreja em um contexto de ditaduras militares e de crescente mobilização e organização social na América Latina.

É sobre esse ponto específico que vamos tratar, apresentando a compreensão de CEBs que aparece nas conferências de Medellín e de Puebla e indicando desafios e perspectivas para as CEBs no contexto eclesial que progressivamente vai se desenhando e se impondo na América Latina a partir dos anos 80, sobretudo a partir da Conferência de Santo Domingo em 1992, no contexto da chamada "nova evangelização".

\section{I - CEBS nas conferências de Medellín e Puebla}

Vamos começar mostrando como as CEBs aparecem e são tratadas nos documentos finais dessas conferências: em que contexto ou parte do documento elas aparecem e como elas são compreendidas e apresentadas aí. Trata-se de uma abordagem textual e de cunho analítico; uma abordagem limitada que prescinde ou, pelo menos, não explicita nem desenvolve aspectos importantes e determinantes da própria redação do texto (o que está por trás do texto); mas que é muito importante para compreender a recepção do documento e o dinamismo eclesial que essa recepção produz (uso do texto).

\section{Documento de Medellín}

Medellín marca oficialmente o processo de recepção do Concílio na América Latina e faz isso mediante processo de inserção da Igreja na realidade latino-americana e de compromisso com os pobres e marginalizados e suas lutas por libertação, como bem indica o tema central dessa conferência: "A Igreja na atual transformação da América Latina à luz do Concílio Vaticano II" (GODOY - AQUINO JÚNIOR, 2017; SOUZA - SBARDELOTTI, 2018; AQUINO JÚNIOR, 2018a, p. 576-599). É nesse contexto e nesse horizonte mais amplos da conferência que se deve situar e entender o lugar, a importância e a compreensão das CEBs no documento final.

Embora haja referências pontuais no texto sobre catequese (CELAM, 2010, p. 129), no texto sobre a liturgia (CELAM, 2010, p. 140) e no texto sobre a formação do clero (CELAM, 2010, p. 190), é na terceira parte do documento que trata da "Igreja e suas estruturas", mais concretamente no texto dedicado à pastoral de conjunto que se trata das CEBs ou das "comunidades cristâs de base".

Como todos os textos do Documento de Medellín, o texto sobre pastoral de conjunto está estruturado em três partes. Começa constatando alguns "fatos" referentes às estruturas pastorais na América Latina. Oferece algumas "orientações doutrinais" a serem consideradas no processo de revisão e renovação das estruturas eclesiais. E, por fim, apresenta algumas "orientaçóes pastorais" para a renovação das estruturas eclesiais em vista de uma pastoral de conjunto.

E é precisamente na terceira parte do texto que se trata das CEBs. Falando da renovação das estruturas pastorais, apresenta-se vários âmbitos de vivência eclesial e articulação pastoral (comunidades cristâs de base, paróquias, vicariatos forâneos e zonas, dioceses, conferências episcopais, organismos continentais) e outras exigências da pastoral de conjunto (renovação pessoal e planejamento pastoral). 
As "comunidades cristâs de base" aparecem, assim, no contexto mais amplo da estrutura eclesial e como âmbito primeiro e mais fundamental de comunhão eclesial: como "comunidade local ou ambiental" deve ter "uma dimensão tal que permita a convivência pessoal fraterna entre seus membros"; deve se constituir sempre mais em "família de Deus", "comunidade de fé, esperança e caridade"; é o "primeiro e fundamental núcleo eclesial”, responsável, em seu nível, pela "riqueza e expansão da fé" e pelo "culto que é sua expressáo"; é "célula inicial da estrutura eclesial e foco de evangelizaçáo e, atualmente, fator primordial da promoção humana e do desenvolvimento"; fundamental para essas comunidades são seus "lideres ou dirigentes" (desejável que pertençam à comunidade, sua escolha e formação deve ter "acentuada preferência na preocupação de párocos e bispos"); seus membros devem exercer as funçóes "sacerdotal, profética e real", fazendo da comunidade "um sinal da presença de Deus no mundo"; recomenda-se "estudos sérios, de caráter teológico, sociológico e histórico, a respeito dessas comunidades cristâs de base" e que "as experiências que forem realizadas sejam divulgadas pelo CELAM e coordenadas na medida do possível"; Tudo isso deve levar a "fazer da paróquia um conjunto pastoral vivificador e unificador das comunidades de base" (CELAM, 2010, p. 207ss).

Em síntese, elas são apresentadas e propostas 1) como pequenas comunidades que permitem a "convivência pessoal fraterna"; 2) como "comunidades de fé, esperança e caridade"; 3) como "primeiro e fundamental núcleo eclesial" ou "célula inicial da estrutura eclesial” e como renovação da paróquia; 4) como "foco de evangelização" e "fator primordial de promoção humana"; 5) como comunidades que têm seus "lideres ou dirigentes" e em que todos os membros assumem a missão "sacerdotal, profética e real"; 6) enfim, como "um sinal da presença de Deus no mundo".

\section{Documento de Puebla}

A Conferência de Puebla (SOUZA - SBARDELOTTI, 2019) acontece em meio a um processo intenso e tenso de renovação pastoral da Igreja latino-americana. Ela recolhe os frutos de uma década fecunda de renovação pastoral a partir do compromisso com os pobres e se enfrenta com a crescente e cada vez mais articulada resistência e oposição ao dinamismo eclesial desencadeado por Medellín. Dom Aloísio Lorscheider, que foi um dos co-presidentes de Puebla, chama atenção para as tentativas de "neutralizar Medellín" por parte de um grupo de bispos e com apoio do Vaticano. Falando das polêmicas em torno da opção pelos pobres, diz que, em determinado momento, o cardeal Baggio, representante do Vaticano na Conferência, "queria telegrafar para o papa [João Paulo II] para dizer que suprimisse o capítulo primeiro da quarta parte do documento que trata da 'opção preferencial pelos pobres"' (TURSI - FRENCKEN, 2008, p. 79s). No final, acabou prevalecendo e se impondo a posição que confirmava as linhas fundamentais de Medellín, dentre elas a importância e centralidade das CEBs na Igreja (BOFF, L, 1981, p. 82-96; TEIXEIRA, 1988, p. 290-303; SOUZA, 1999, p. 223-234).

Em sintonia com a Exortação Apostólica Evangelii Nuntiandi sobre a evangelização no mundo contemporâneo, Puebla tratou da "evangelização no presente e no futuro da América Latina". O Documento Final está organizado em cinco partes: visão pastoral da realidade latino-americana, desígnio de Deus sobre a realidade latino-americana, evangelização na Igreja da América Latina, Igreja missionária a serviço da evangelização na América Latina, sob o dinamismo do Espírito: opçôes pastorais. 
Embora haja muitas referências pontuais às CEBs ao longo do documento, elas são abordadas de modo mais amplo e sistemático na terceira parte do documento dedicada à "evangelizaçáo na Igreja da América Latina", concretamente no primeiro capítulo que trata dos "centros de comunhão e participação": família, CEBs, paróquia, Igreja particular. São abordadas, portanto, no contexto mais amplo da Igreja como "povo de Deus" (comunhão e participação) que se realiza "em diversos níveis e sob diversas formas históricas" (CELAM, 1986, n. 618).

O texto está estruturado em três pontos:

O primeiro ponto faz algumas constatações sobre a "situação" da Igreja na América Latina em seus diversos níveis. Com relação às "pequenas comunidades, sobretudo as comunidades eclesiais de base" (esse "sobretudo" é novo em relação à Medellín!), constata que elas "criam maior inter-relacionamento pessoal, aceitação da Palavra de Deus, revisão de vida e reflexão sobre a realidade à luz do Evangelho" e que nelas se acentua o "compromisso com a família, com o trabalho, o bairro e a comunidade local"; destaca com "alegria" e como "fato eclesial relevante e caracteristicamente nosso" e até mesmo como "esperança da Igreja" sua "multiplicação", sobretudo "na periferia das grandes cidades e no campo"; reconhece que elas são um "ambiente propício para o surgimento de novos serviços leigos" e que nelas "a catequese familiar e a educaçâo dos adultos na fé" têm se difundido e se desenvolvido de "forma mais adequada ao povo simples"; afirma que "não se deu suficiente atenção à formação" das lideranças e que talvez por isso alguns membros de comunidade ou algumas comunidades "vão perdendo o autentico senso eclesial" (CELAM, 1986, n. 629-630).

O segundo ponto oferece elementos para uma "reflexão doutrinal": "o cristáo vive em comunidade sob a ação do Espírito Santo" que é princípio de "unidade e comunhão" e de "unidade e variedade de estados de vida, ministérios e carismas"; "nas pequenas comunidades cresce a experiência de novas relaçôes interpessoais na fé, o aprofundamento da palavra de Deus, a participação na eucaristia, a comunhão com os pastores da Igreja particular e um maior compromisso com a justiça na realidade social dos ambientes em que se vive"; CEB: a) "enquanto comunidade, integra famílias, adultos e jovens, numa íntima relação interpessoal na fé", b) "enquanto eclesial, é comunidade de fé, esperança e caridade, celebra a palavra de Deus e se nutre da eucaristia [...], realiza a palavra de Deus na vida, através da solidariedade e compromisso com o mandamento novo do Senhor e torna presente e atuante a missão eclesial e a comunhão visível com os legítimos pastores, por intermédio do ministério de coordenadores aprovados", c) "é de base por ser constituída de poucos membros, em forma permanente e à guisa de célula da grande comunidade"; seus membros "procuram uma vida mais evangélica no seio do povo, colaboram para questionar as raízes egoístas e de consumismo da sociedade e explicitam a vocação para a comunhão com Deus e com os irmãos, oferecendo um valioso ponto de partida para a construção duma nova sociedade, 'a civilização do amor"; as CEBs "são expressão de amor preferencial da Igreja pelo povo simples; nelas se expressa, valoriza e purifica sua religiosidade e se lhe oferece possibilidade concreta de participaçáo na tarefa eclesial e no compromisso de transformar o mundo" (CELAM, 1986, n. 638-643).

O terceiro ponto apresenta algumas "linhas pastorais": "queremos resolutamente promover, orientar e acompanhar as comunidades eclesiais de base, de acordo com o espírito de Medellín e os critérios da Evangelii nuntiandi"; "favorecer o descobrimento e a formação gradual de animadores para elas"; buscar meios de adaptação "à pastoral das grandes cidades do nosso continente" (CELAM, 1986, n. 648). 
Em linhas gerais, retoma-se e reafirma-se o que se diz em Medellín com alguns matizes e destaques: 1) aparece uma distinção entre pequenas comunidades e CEBs; 2) explicita-se melhor a identidade das CEBs enquanto comunidade (poucos membros, relação interpessoal) eclesial (fé-esperança-caridade, palavra de Deus e sacramentos, palavra de Deus na vida, missáo, comunháo com os pastores) de base (poucos membros, permanente, célula da grande Igreja, expressão do amor preferencial da Igreja pelo povo simples); 3) reafirma-se a participação de todos na tarefa eclesial e o compromisso com a justiça, a transformação do mundo e a construção da nova sociedade; 4) destaca-se o desafio da formação de lideranças e de adaptação nas grandes cidades; 5) e reafirma-se o compromisso de "promover, orientar e acompanhar" as CEBs de acordo com "o espírito de Medellín e os critérios da Evagelii nuntiandi".

\section{Lugar e importância das CEBs em Medellín e Puebla}

As CEBs aparecem nas conferências de Medellín e de Puebla no contexto e no horizonte mais amplos de recepção do Concílio e renovação da Igreja na América Latina: O "povo de Deus" tem sua concretização mais básica e elementar na "comunidade eclesial de base" e sua missão consiste em ser "sinal e instrumento" de salvação ou do reinado de Deus no mundo, que se realiza na vida fraterna e no compromisso com os pobres e marginalizados. Elas aparecem, portanto, como elemento fundamental da estrutura da Igreja ("primeiro e fundamental núcleo eclesial", "célula inicial da estrutura eclesial") e como lugar e forma privilegiados de exercício de sua missão no mundo (vida fraterna, opção pelos pobres e compromisso com a justiça) e são apresentadas oficialmente como projeto pastoral ou, em todo caso, como elemento fundamental do projeto pastoral que se desenha e se propóe para o conjunto da Igreja.

Esse aspecto institucional das CEBs foi fundamental para o seu desenvolvimento quantitativo e qualitativo e para sua importância na Igreja e na sociedade. Não obstante suas ambiguidades e contradiçóes, sem ele não se pode entender adequadamente as CEBs nem muito menos o florescimento e o impacto sócio-eclesial que tiveram nas décadas de 70 e 80 . Tanto que, na medida em que a Igreja latino-americana - sobretudo a partir da segunda metade dos anos 80 - vai tomando outros rumos pastorais, as CEBs vão progressivamente perdendo força, relevância e espaço no conjunto da Igreja.

\section{II - Novo contexto eclesial: desafios e perspectivas}

No item anterior, situamos o nascimento e o desenvolvimento das CEBs no contexto mais amplo de renovação eclesial desencadeado pelo Concílio Vaticano II e sua recepção na América Latina, a partir das conferências de Medellín e Puebla. Agora vamos fazer algumas consideraçóes sobre as CEBs no novo contexto eclesial que vai se desenvolvendo e se impondo a partir do final dos anos 80, sobretudo, a partir da Conferência de Santo Domingo em 1992.

\section{Novo contexto eclesial}

Se não se pode compreender a importância e o impacto sócioeclesiais das CEBs nos anos 70 e 80 na América Latina fora do processo de renovação eclesial desencadeado pelo Concílio Vaticano (Igreja como Povo de Deus - sacramento de salvação no mundo), tampouco se pode compreender sua marginalização 
eclesial a partir dos anos 80 sem considerar o novo cenário eclesial que aos poucos vai se configurando e se impondo a partir de Roma (clericalismo, eclesiocentrismo) e terá em Santo Domingo um marco importante. Se antes elas apareciam como projeto pastoral ou, em todo caso, como parte integrante e fundamental do projeto pastoral que se desenhava e se propunha para o conjunto da Igreja latino-americana, agora, perdem centralidade institucional e, na melhor das hipóteses, são toleradas como uma expressão eclesial entre outras - uma expressáo marginal no contexto de uma Igreja cada vez mais centrada em si mesma (missão) e cada vez mais clerical (estrutura).

É verdade que se continuará falando de CEBs na Igreja, inclusive nos documentos do CELAM e das conferências episcopais. Mas, além da preferência institucional por outras nomenclaturas como "pequenas comunidades" ou "comunidades eclesiais missionárias" e das suspeitas, advertências e correçôes que normalmente acompanham ou estão por trás dessas falas, a perspectiva eclesial é bem outra: Por um lado, as CEBs já não aparecem mais como o "núcleo fundamental" ou a "célula inicial" da estrutura eclesial, mas como uma organização ou mesmo como um movimento entre outros. Por outro lado, e isso é ainda mais grave e determinante, vai se impondo uma compreensão de missão ou evangelização (a chamada "nova evangelização") de caráter marcadamente religioso e doutrinal que, embora não negue explicita e teoricamente, na prática, aos poucos, vai relativizando e mesmo prescindindo do envolvimento com os problemas sociais e do compromisso com os pobres e a justiça social. Trata-se de um processo sutil e progressivo (mais prático que teórico) de fechamento ao mundo e auto-centramento eclesial. Um verdadeiro “ajuste pastoral” (BOFF, C, 1994, p. 25-70; AQUINO JÚNIOR, 2014, p. 109-117).

Essa perda de centralidade institucional repercutiu muito na importância e no lugar da CEBs no conjunto da Igreja. É cada vez menor o número de comunidades que se reconhecem como CEBs e, menor ainda, o número de comunidades que se identificam e assumem com convicção essa forma de ser Igreja. Boa parte das comunidades que existem hoje e de suas lideranças nunca ouviu falar de CEBs. Além do mais, e isso é o mais grave, esse modo de ser Igreja, envolvido com os problemas do mundo, comprometido com os pobres e marginalizados e suas lutas e organizaçóes, é cada vez mais marginal e estranho na Igreja. A imensa maioria das comunidades está reduzida a culto e doutrina e tem um caráter marcadamente devocional-pentecostal. Mesmo quando se insiste institucionalmente na dimensão comunitária da fé, como o Documento 100 da CNBB Comunidade de comunidades: Uma nova Paróquia (CNBB, 2014) e as Diretrizes da Ação Evangelizadora da Igreja no Brasil 2019-2023 (CNBB, 2019), o compromisso com os grandes problemas do mundo e a colaboração com a transformação da sociedade (que já nem aparece mais no Objetivo Geral da Ação Evangelizadora da Igreja no Brasil) aparece como algo marginal e secundário. Nunca negado, até afirmado, mas sempre secundário em relação ao que é central e decisivo: a vida interna da comunidade eclesial... E isso apesar de toda insistência profética do Papa Francisco numa "Igreja pobre e para os pobres" ou numa "Igreja em saída para as periferias" (AQUINO JÚNIOR, 2019a; 2019b).

Fato é que esse jeito de ser Igreja foi sendo progressivamente sufocado e marginalizado no conjunto da Igreja. E não só do ponto de vista da orientação e condução pastoral por parte dos ministros ordenados, mas também, e o que é pior, do ponto de vista das bases da Igreja e de suas lideranças. Sem esquecer nem desconsiderar o papel decisivo das mídias religiosas de cunho pentecostal-devocional-conservador (católicas e protestantes) na construção do imaginário religioso e na vivência da fé. Temos uma Igreja profundamente autocentrada e clerical. Isso ajuda a compreender, inclusive, as resistências que o papa Francisco tem encontrado em seu projeto de renovaçáo eclesial - um verdadeiro "cisma branco" em 
que, mesmo quando não se faz críticas abertas e até se tece elogios a ele ("o santo padre") e o cita (muito seletivamente!), não se leva a sério ou mesmo se boicota suas orientações pastorais (AQUINO JÚNIOR, 2018b, p. 41-58). Tudo isso desafia as CEBs a repensar seu lugar (cada vez mais marginal) e sua atuação (cada vez mais profética) no conjunto da Igreja.

\section{Desafios e perspectivas}

Nesse novo contexto eclesial, as CEBs ocupam um lugar marginal no conjunto da Igreja. Em geral, na melhor das hipóteses, são aceitas ou toleradas como uma entra as muitas expressóes eclesiais e uma expressão pouco relevante e pouco atraente. E isso tem gerado muitas desilusões e tem desafiado suas lideranças a encontrar formas criativas e eficazes de "conservar a fé" em um mundo e em uma Igreja que, sob muitos aspectos, vão na contramão do Evangelho de Jesus Cristo.

Parte de suas lideranças históricas mais convictas e criativas foi sendo marginalizada e excluída das instancias de articulação e coordenação pastoral das paroquias e dioceses e/ou se desiludindo e se afastando dessas instancias e, aos poucos, perdendo espaço nas comunidades e pastorais. Mesmo conservando a fé e se reconhecendo como Igreja, não encontra mais espaço ou não se encontra mais nos atuais espaços eclesiais (excessivamente devocionais e reduzidos a culto e doutrina e com mentalidades e relaçóes de poder profundamente clericais). Essa situação, dolorosa e compreensível, acaba produzindo na vida de algumas pessoas um processo de des-eclesialização da fé que é trágico para a própria vivência da fé. Uma nova versão do "Jesus Cristo, sim; Igreja, não". Esse processo de des-eclesialização da fé se dá tanto medida em que se prescinde explicitamente da comunidade (não é necessária), quanto, e de modo mais sutil, na medida em que, mesmo afirmando sua importância, não se vincula a nenhuma comunidade real/concreta (idealização da comunidade). E isso é trágico para a própria vivência da fé porque compromete um aspecto fundamental da fé que é constituir-nos como comunidade ("povo de Deus", "corpo de Cristo", "templo do Espírito") e porque, ao prescindir da comunidade real/concreta, acaba reduzindo a fé a uma questáo individual e dissolvendo seu caráter de corpo e/ou de força social e, assim, comprometendo sua eficácia no mundo.

Outras lideranças, por sua vez, têm resistido profética e criativamente em comunidades de base, em pastorais, organismos e serviços sociais, em estruturas paroquiais e diocesanas e em articulaçóes de setores populares da Igreja. Sabem que a Igreja, nas últimas décadas, tomou um rumo bem diferente e sob muitos aspectos até contrário aos rumos dados pelo Concílio Vaticano II e sua recepção na América Latina a partir da Conferência de Medellín. Na linguagem do papa Francisco, foi se tornando cada vez mais uma Igreja autoreferencial e autocentrada (em vez de uma "Igreja em saída para as periferias") e uma Igreja clerical (em vez de uma Igreja povo de Deus com seus carismas e ministérios). Mas sabem também que a fé nos faz Igreja e se vive em Igreja (comunidade concreta/real e não apenas ideal), que a missão se realiza como Igreja e não apenas como indivíduos (corpo ou força social) e não abrem mão desse aspecto fundamental da fé e da missão. Por isso, resistem profética e criativamente na vivência eclesial da fé e no exercício eclesial da missão. E de muitas formas: participando de comunidades e pastorais; assumindo serviços ou ministérios na comunidade; articulando comunidades e setores populares da Igreja; sensibilizando comunidades e pastorais com os problemas e as lutas do povo; vinculando esses problemas e essas lutas à catequese, à leitura da bíblia e à liturgia; atentando para as diversas situaçóes de sofrimento que marcam a vida de tanta gente; fazendo trabalho de base com adultos, crianças, adolescentes e jovens; despertando, cultivando e acompanhando novas lideranças; participando e/ou fortalecendo as pastorais, organismos e 
serviços sociais na Igreja; mobilizando atividades eclesiais que abrem a Igreja para aos grandes problemas do mundo (Campanha da Fraternidade, grito dos excluídos, semanas sociais, marchas por direitos, defesa de comunidades e grupos marginalizados e injustiçados etc.); apoiando e participando de lutas e organizaçóes populares etc. Fazem isso num ambiente eclesial extremante adverso, não sem dificuldades e até sofrimento; mas como aspecto fundamental e irrenunciável da forma cristã de viver a fé e assumir a missão que nos foi confiada.

Fato é que as CEBs, como jeito de viver a fé e ser Igreja, têm cada vez mais um lugar marginal e uma atuação profética no conjunto da Igreja. Mais do que nunca têm que assumir características de "fermento", de "sal", de "luz", de "semente". E isso em um contexto social e eclesial adversos.

\section{Conclusão}

Se as CEBs aparecem nos anos 1960-1980 como elemento fundamental da estrutura eclesial na América Latina (centralidade institucional), a partir da segunda metade dos anos de 1980 elas vão se tornando uma organização entre outras na Igreja e, cada vez mais, uma organização marginal ou mesmo tolerada (marginalização institucional). Essa mudança de lugar institucional das CEBs se explica, sobretudo, pela mudança de projeto eclesial na Igreja. As CEBs estão vinculadas à eclesiologia do Vaticano II e sua recepção/tradução latino-americana a partir de Medellín: Povo de Deus ou comunidade com seus carismas e ministérios; sacramento de salvação ou libertação. Na medida em que essa perspectiva de Igreja vai perdendo espaço para uma eclesiologia clerical e autocentrada, as CEBs vão perdendo espaço no conjunto da Igreja. Não se trata apenas de mudança de sigla ou nomenclatura. Trata-se de mudança de perspectiva eclesial. A mudança de sigla ou nomenclatura é apenas indício ou sintoma de uma mudança mais radical.

A pretensão desse texto era chamar atenção para essa mudança profunda de perspectiva eclesial na América Latina a partir da segunda metade da década de 1980 como fator determinante e decisivo do processo de marginalizaçáo institucional das CEBs. Sem levar a sério esse fato não se entende a situação atual das CEBs na Igreja nem se podem pensar caminhos eficazes de atuação. É importante ter presente que a resistência que o papa Francisco encontra na Igreja se deve, em última instância, ao mesmo fato. A mudança de rumos na Igreja nas últimas décadas foi tão drástica que nem mesmo o papa, com toda força institucional que tem, consegue mudar assim tão facilmente. E não nos iludamos: a resistência não está só nos ministros ordenados; está também nas bases da Igreja. Trata-se de uma compreensão e de uma forma de Igreja profundamente clericais e autocentradas. E isso nos desafia.

Não dá para fazer de conta que nada mudou e continuar organizando grandes encontros intereclesiais como se as CEBs fossem a base de toda Igreja. Não dá para ignorar a sensibilidade atual para questôes subjetivas e cotidianas tão bem captada pelos movimentos pentecostais. Não adianta criticar e lamentar os novos rumos da Igreja sem se dispor a viver e construir na base o jeito de ser Igreja das CEBs. Não dá para coordenar e articular as CEBs sem fazer parte de nenhuma comunidade concreta. Não adianta idealizar e celebrar o passado com suas lutas, seus profetas e mártires sem assumir com seriedade o tempo que nos toca viver: seus desafios, suas lutas, suas profecias. Tampouco adianta admirar e aplaudir o papa Francisco em seu empenho profético por uma "Igreja pobre e para os pobres" ou uma "Igreja em saída 
para as periferias" sem se dispor a viver e animar no dia-dia esse jeito de ser Igreja, mesmo que marginal e na contramão do modelo clerical e auto-referencial que se impôs nas últimas décadas, como faz o papa Francisco e como fizeram todos os profetas e movimentos proféticos ao longo da história.

Não basta lamentar o passado e criticar o presente. Importa atualizar crítica e criativamente esse jeito de ser Igreja no contexto eclesial e social em que estamos inseridos. Sempre nos passos de Jesus de Nazaré, na fidelidade ao Evangelho do reinado de Deus, na força do Espírito, no serviço aos pobres e marginalizados.

\section{Referências}

Aquino Júnior, F. (2011). “'Novas' diretrizes da ação evangelizadora: ‘Ajuste Pastoral’!?”. REB 248, p. 926-91. https://doi.org/10.29386/reb.v71i284.971

Aquino Júnior, F. (2018a). "Medellín - centralidade dos pobres na Igreja: Clamores e resistências atuais". Revista Horizonte 16/50, p. 576-599. https://doi.org/10.5752/P.2175-5841.2018v16n50p576-599

Aquino Júnior, F. (2018b). "50 anos de Medellín - 5 anos de Francisco: Perspectivas teológico-pastorais". Perspectiva Teológica 50, p. 41-58. https://doi.org/10.20911/21768757v50n1p41-58/2018

Aquino Júnior, F. (2019a). Renovar toda a Igreja no Evangelho: Desafios e perspectivas para a conversão pastoral da Igreja. Aparecida: Santuário.

Aquino Júnior, F. (2019b). “Diretrizes Gerais da Ação Evangelizadora da Igreja no Brasil 2019-2023”. Perspectiva Teológica 51, p. 539-554. https://doi.org/10.20911/21768757v51n3p539/2019

Boff, C. (1994). O "Evangelho" de Santo Domingo: Os dez temas-eixos do Documento do CELAM. Petrópolis: Vozes.

Boff, C. et al. (1997). As comunidades de Base em questão. São Paulo: Paulinas.

Boff, L. (1981). O caminhar da Igreja com os oprimidos: Do Vale de Lágrimas à Terra Prometida. Rio De Janeiro: CODECRI.

BOFF, L. (1991). E a Igreja se fez povo. Eclesiogênese: A Igreja que nasce da fé do povo. Petrópolis: Vozes.

CELAM. (1986). Evangelização no presente e no futuro da América Latina. Conclusões da Conferência de Puebla: Texto Oficial. São Paulo: Paulinas.

CELAM. (2010). “Conclusões de Medellín”. In: Conclusões da Conferência de Medellín - 1968. Trinta anos depois, Medellín ainda é atual? São Paulo: Paulinas, p. 37-223.

CNBB. (2012). Missão e ministérios dos cristãos leigos e leigas. São Paulo: Paulinas.

CNBB. (2014). Comunidade de comunidades: Uma nova paróquia. A conversão pastoral da paróquia. São Paulo: Paulinas.

CNBB. (2019). Diretrizes Gerais da Ação Evangelizadora da Igreja no Brasil 2019-2023. Brasília: CNBB.

Godoy, M. \& Aquino Júnior, F. (2017). 50 anos de Medellín: Revisitando os textos, retomando o caminho. São Paulo: Paulinas. https://doi.org/10.20911/21768757v50n1p41-58/2018 


\section{Estructura, análisis narratológico y contextual de Jn 7, 53-8, 11}

Matos, H. C. J. (1985). CEBs: Uma interpelação para ser cristão hoje. São Paulo: Paulinas.

Muñoz, R. (1985). A Igreja no povo: Para uma eclesiologia latino-americana. Petrópolis: Vozes.

Philips, M. (1968). A Igreja e seu mistério no II Concílio do Vaticano. História, texto e comentário da Constituição Lumen Gentium. Tomo I. São Paulo: Herder.

Souza, L. A. G. (1999). “A caminhada de Medellín a Puebla”. Perspectiva Teológica 31, p. 223-234.

Souza, N. \& Sbardalotti, E. (org.). (2018). Medellín: Memória, profetismo e esperança na América Latina. Petrópolis: Vozes.

Souza, N. \& Sbardalotti, E. (org.). (2019). Puebla: Igreja na América Latina e no Caribe. Opção pelos pobres, libertação e resistência. Petrópolis: Vozes.

Teixeira, F. L. C. (1988). A gênese das CEB's no Brasil: Elementos explicativos. São Paulo: Paulinas.

Tursi, C. \& Frencken, G. (2008). Mantenham as lâmpadas acesas: Revisitando o caminho, recriando a caminhada. Um diálogo de Aloísio Cardeal Lorscheider com O Grupo. Fortaleza: UFC. 